\title{
МАРКЕТИНГОВЫЕ ОСОБЕННОСТИ ОРГАНИЗАЦИОННОГО ВЫБОРА АУДИТОРА В УСЛОВИЯХ РАЗВИТОЙ КОНКУРЕНЦИИ
}

\author{
(c) 2021 Любофеев Владимир Дмитриевич \\ кандидат экономических наук, \\ аудитор ООО «Аудит-Универсал», Россия, Краснодар
}

Статья посвящена маркетинговым особенностям организационного выбора аудитора в условиях развитой конкуренции. На основани имеющихся данных делается вывод об усилении конкуренции на рынке аудиторских услуг. На основе анализа факторов, влияющих на организационный выбор аудитора, предлагается модель количественной оценки конкурентных преимуществ аудитора и методика выбора.

Ключевые слова: аудитор, рынок аудиторских услуг, конкуренция, ценовые факторы, факторы непосредственной лояльности, факторы косвенной лояльности, тип потребительского поведения, тендер.

Рынок аудиторских услуг в Российской Фе-

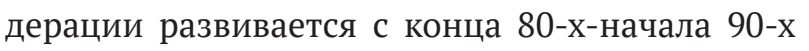
годов прошлого века, когда в нашей стране открылись офисы фирм «большой шестерки» (общепринятое собирательное имя фирм Arthur Andersen, KPMG, Ernst \& Young, Coopers \& Lybrand, Deloitte \& Touche, Price Waterhouse).

Общий объем рынка аудиторских услуг за 2010-2019 годы по данным ежегодных отчетов Минфина России показывал незначительный номинальный рост (Таблица 1). В течение всего этого периода темпы роста рынка аудиторских услуг были неизменно ниже публикуемых Федеральной службой государственной статистики темпов роста ВВП. Фактически имеющиеся данные отражают непрекращающееся сокращение рынка аудиторских услуг в нашей стране. Одновременно сокращалось и количество аудиторов.

В результате сокращения количества аудиторов темпы роста рынка аудиторских услуг в расчете на одного аудитора были несколько выше, чем темпы роста объема рынка в целом, однако за десятилетие они также значительно отстали от темпов роста ВВП.

В настоящее время продолжается реформирование рынка аудиторских услуг. В конце 2020 года был принят Федеральный закон от 29.12.2020 N 476-Ф3 «О внесении изменения в статью 5 Федерального закона «Об аудиторской деятельности», значительно сокращающий круг подлежащих обязательному аудиту организаций, что по общему мнению приведет к даль-

Таблица 1. Объем и динамика рынка аудиторских услуг в сопоставлении с общей динамикой ВВП за 2010-2019 годы

\begin{tabular}{|c|c|c|c|c|c|c|}
\hline Год & $\begin{array}{c}\text { Количество } \\
\text { аудиторов на } \\
\text { конец года*, } \\
\text { тыс [5] }\end{array}$ & $\begin{array}{c}\text { Объем рынка } \\
\text { велом, млрд. } \\
\text { руб. [5] }\end{array}$ & $\begin{array}{c}\text { Объем рынка } \\
\text { в расчете на } \\
\text { аудора, млн. } \\
\text { руб. [5] }\end{array}$ & $\begin{array}{c}\text { Темп роста } \\
\text { рынка в целом } \\
\text { (в \% к пред. } \\
\text { году) [5] }\end{array}$ & $\begin{array}{c}\text { Темп роста } \\
\text { объема рынка } \\
\text { в расчете на } \\
\text { аудитора (в \% к } \\
\text { пред. году) [5] }\end{array}$ & $\begin{array}{c}\text { Темп роста } \\
\text { ВВП (в \% к } \\
\text { пред. году) [7] }\end{array}$ \\
\hline 2010 & 6,1 & 49,1 & 8,0 & - & - & - \\
\hline 2011 & 6,2 & 50,8 & 8,2 & $103 \%$ & $102 \%$ & $130 \%$ \\
\hline 2012 & 5,7 & 51 & 8,9 & $100 \%$ & $109 \%$ & $113 \%$ \\
\hline 2013 & 5,5 & 52,2 & 9,5 & $102 \%$ & $106 \%$ & $107 \%$ \\
\hline 2014 & 5,3 & 53,6 & 10,1 & $103 \%$ & $107 \%$ & $108 \%$ \\
\hline 2015 & 5,1 & 56,1 & 11,0 & $105 \%$ & $109 \%$ & $105 \%$ \\
\hline 2016 & 5 & 57,1 & 11,4 & $102 \%$ & $104 \%$ & $103 \%$ \\
\hline 2017 & 4,8 & 55,4 & 11,5 & $97 \%$ & $101 \%$ & $107 \%$ \\
\hline 2018 & 4,7 & 58,5 & 12,4 & $106 \%$ & $108 \%$ & $113 \%$ \\
\hline 2019 & 4,5 & 57,1 & 12,7 & $98 \%$ & $102 \%$ & $105 \%$ \\
\hline
\end{tabular}

\footnotetext{
* - включает аудиторские организации и индивидуальных аудиторов
} 
нейшему сокращению рынка аудиторских услуг. Постановление Правительства от 19.04.2021 № 622 «Об ограничениях на предоставление информации и документации аудиторской организации, индивидуальному аудитору» добавило неопределенности на рынке аудиторских услуг, так как по некоторым оценкам оно может привести к новому переделу рынка.

Сложившаяся на рынке аудиторских услуг ситуация приведет с значительному усилению конкуренции. В этих условиях важнейшим конкуретным преимуществом аудиторской компании является эффективная работа с клиентами в процессе организационного выбора аудитора и понимание маркетинговых собенностей этого процесса.

В процессе выбора аудитора клиент изучает ряд неравнозначных факторов, в большинстве случаев анализируемых последовательно.

Первым фактором является соответстветствие аудитора законодательным требованиям. Общие законодательные требования к аудиторам содержатся в Федеральном законе от 30.12.2008 N 307-Ф3 «Об аудиторской деятельности», а специфические установлены отраслевым законодательством.

Анализ последующих факторов опирается на тип потребительского поведения клиента, который определяется его нуждами, потребностями и запросами [12].

На рынке аудиторских услуг целесообразно рассматривать три группы влияющих на потребительское поведение факторов: ценовые, непосредственной лояльности, косвенной лояльности. Потребительское поведение является функцией указанных трех групп факторов.

На практике могут существовать ситуации, когда во внимание принимаются только ценовые факторы. Это чаще всего имеет место в случаях обязательного аудита, когда достижение целей аудита не является важным для клиента или законодательством определена процедура выбора аудитора.

Достижение целей аудита может не являться важным для клиента в частности, при аудите акционерных обществ, которые имеют в составе собственников и значимых кредиторов небольшой круг лиц, а также организаций, подлежащих обязательному аудиту исключительно по стоимостным критериям [11]. В соответствии с международными стандартами аудита целью аудита является повышение степени уверенности предполагаемых пользователей в финансовой отчетности [2]. Также популярно мнение, что аудит это процесс уменьшения до приемлемого уровня информационного риска для пользователей финансовых отчетов, в контексте которого информационный риск - это вероятность того, что в финансовых отчетах, публикуемых компанией, содержатся ложные или неточные сведения [13]. В соответствии с правилами составления бухгалтерской отчетности, установленными в Российской Федерации, ошибка признается существенной, если она в отдельности или в совокупности с другими ошибками за один и тот же отчетный период может повлиять на экономические решения пользователей [9]. В описываемой ситуации собственники и кредиторы могут получить достаточную степень уверенности в финансовой отчетности и без проведения аудита, а также использовать для принятия экономических решений бухгалтерскую отчетность в сокращенном объеме, недостаточном для проведения аудита в соответствии с международными стандартами. Следствием этого является отношение к оплате за аудиторскую проверку как к неизбежному индивидуально-безвозмездному платежу - чем меньше, тем лучше. В этой ситуации определяющим критерием выбора аудитора является цена, а сам процесс выбора сводится к ранжированию по цене поступивших от аудиторов предложений.

В ряде случаев процедура выбора аудитора определена законодательством. В частности, при заключении договора на проведение обязательного аудита бухгалтерской (финансовой) отчетности организаций с госучастием [11] выбор аудитора осуществляется на тендерной основе и по оценкам экспертов в качестве критерия отбора продолжает доминировать цена [4]. Выбор аудитора в этом случае обычно осуществляется на основании тендера.

В ситуациях, когда потребительское поведение опирается не только на ценовые факторы, для выбора аудитора используются закрытый сбор предложений или открытый тендер. В обоих случаях может использоваться единая предлагаемая автором методика отбора аудитора. В основе методики лежит балльная оценка каждого аудитора, а договор оказанния аудиторских услуг заключается с аудитором, получившим в результате оценки максимальное количество 
баллов. Получаемое аудтором в процессе оценки количество баллов определяется по формуле (1).

$$
\mathrm{T}=\mathrm{K} 1 \times \mathrm{P}+\mathrm{K} 2 \times \mathrm{DL}+\mathrm{K} 3 \times \mathrm{IL},
$$

Где: Т - общее количество баллов; Р - количество баллов по ценовым факторам; DL - количество баллов по факторам непосредственной лояльности; IL - количество баллов по факторам косвенной лояльности; К1, К2, К3 - весовые коэффициенты учета каждой из групп факторов в общей оценке.

Определение количества баллов по ценовому фактору определяется путем ранжирования поступивших от аудиторов предложений по цене. При этом целесообразно исключить из анализа как предложения с чрезмерно высокой ценой как недоступные в рамках имеющегося бюджета, так и предложения с необоснованно низкой ценой как явно неспособные обеспечить приемлемое качество услуг. Остальные предложения ранжируются по принципу возрастания количества присваиваемых баллов по мере уменьшения цены.

Факторы непосредственной лояльности отражают представления потребителя о неценовых конкурентных преимуществах каждого аудитора. Совокупное влияние этих факторов определяется по формуле (2).

$\mathrm{DL}=\mathrm{K} 4 \times \mathrm{R}+\mathrm{K} 5 \times \mathrm{C}+\mathrm{K} 6 \times \mathrm{E}+\mathrm{K} 7 \times \mathrm{I}$,

Где: $\mathrm{R}$ - количество баллов по фактору репутации аудитора; C - количество баллов по фактору комплексности оказываемых услуг; Е - количество баллов по фактору опыта проведения аудита организаций, схожих по сфере и масштабам деятельности; I - количество баллов по фактору страхования профессиональной ответственности аудитора; К4, K5, K6, К7 - весовые коэффициенты учета каждой из групп факторов в общей оценке.

Фактор репутации аудитора является специфической особенностью выбора исполнителя на рынке аудиторских услуг. Важность этого фактора обусловлена тем, что в отличие от большинства иных товаров или услуг качество аудиторской услуги практически невозможно оценить в момент ее оказания. Результат работы аудитора как правило проявляется в будущем, а прибыли или убытки, возникшие вследствии плохой или хорошей работы аудтора, на порядки превышают стоимость услуг. К балльной оценке репутации аудитора возможен как формальный, так и неформальный подход. При неформальном подходе количество баллов, присваиваемых каждому аудитору определяется предпочтениями осуществляющего выбор субъекта. Формальный подход предполагает ранжирование аудиторов на основе оценок общепризнанных рейтинговых агентств. В нашей стране признанная рейтинговая оценка аудиторских компаний содержится в ежегодно публикуемых авторитетным российским рейтинговым агентством РАЭКС-Аналитика исследованиях деятельности аудиторских компаний, формируемых по данным крупнейших аудиторских компаний, верифицированным по официальным статистическим формам [6].

Фактор комплексности оказываемых услуг принимается во внимание, если планируется получение не какой-то отдельной услуги, а комплекса услуг. Баллы по этому фактору присваиваются аудиторам в результате сопоставления перечней необходимых и предлагаемых услуг.

Фактор опыта проведения аудита организаций, схожих по сфере и масштабам деятельности, особенно важен для организаций, осуществляющих диверсифицированную или географически распределенную деятельность. При анализе этого фактора дополнительно нужно принимать во внимание участие аудитора в сетях аудиторских организаций и его опыт проведения совместного аудита [14].

Фактор страхования профессиональной ответственности аудитора важен как инструмент компенсации убытков, возникающих вследствии оказания аудиторских услуг ненадлежащего качества. В настоящее время в соответствии с действующим российским законодательством в качестве квазистрахового инструмента выступает компенсационный фонд [10], [11]. В единственной оставшейся в РФ Саморегулируемой организации аудиторов Ассоциации «Содружество» компенсационный фонд существует с 2009 года и по официальным данным выплат из компенсационного фонда, в том числе выплат по обязательствам членов СРО ААС, возникшим в результате причинения ими вреда за период деятельности СРО ААС, не осуществлялось [8]. Трудно поверить, что за 12 лет существования компенсационного фонда не было случаев причинения ущерба аудиторами своим клиентам вследствии оказания аудиторских услуг ненадлежащего качества. Главный аудитор Банка России, В.П.Горегляд, приводит данные, что в 
2016 г. были отозваны лицензии у 97 кредитных организаций, 68 из них были признаны банкротами. При этом у 59 из них $(86,8 \%)$ имелись аудиторские заключения о достоверности годовой отчетности [1]. По нашему мнению, в сложившихся условиях при балльной оценке по фактору страхования профессиональной ответственности аудитора, следует учитывать страхование профессиональной ответственности аудитора в страховых организациях и суммы возможного страхового возмещения.

Факторы косвенной лояльности являются специфичными для аудиторских услуг. Их существование обусловлено тем, что в мировой практике аудиторская деятельность является общественно значимой, а аудит проводится в интересах внешних пользователей финансовой отчетности, которые должны доверять качеству проведенного аудита. Фактор косвенной лояльности при выборе аудитора может учитываться различными способами в зависимости от того, является ли клиент общественно значимой организацией [11] (по принятой в ЕС терминологии субъектом общественного интереса (public interest entity - PIE) [3]. Если клиент является общественно значимой организацией, то, как правило, ни один из инвесторов или кредиторов не может самостоятельно выбирать аудитора. В этом случае оптимальным методом балльной оценки будет использование общепризнанных рейтингов: на зарубежных финансовых рынках российским компаниям обычно приходится выбирать из большой четверки, а внутри страны можно воспользоваться рейтинговой оценкой аудиторских компаний рейтингового агентства РАЭКС-Аналитика [6]. Если клиент не является общественно значимой организацией, то необходимость проведения аудита возникает преимущественно в случаях банковского кредитования. При этом банки нередко ограничивают выбор аудитора перечнем аккредитованных аудиторских компаний.

Весовые коэффициенты учета факторов в общей оценке К1-К7 определяются экспертным путем на основании индивидуальной оценки значимости базовых факторов.

Использование клиентами аудиторов приведенных маркетинговых особенностей организационного выбора аудитора и учет аудиторами этих особенностей в в условиях развитой конкуренции позволит сократить макроэкономические издержки функционирования института внешнего аудита и обеспечить необходимый уровень доверия к финансовой отчетности со стороны внешних пользователей.

\section{Библиографический список}

1. Горегляд В. П. Современный аудит: проблемы и перспективы//Деньги и кредит.-2017.-№ 2.- c. 6-13.

2. Международный стандарт аудита 200 «Основные цели независимого аудитора и проведение аудита в соответствии с международными стандартами аудита».

3. Никифоров С.Л. Обязательная ротация аудиторских организаций: доводы за и против//Деньги и кредит.-2017.-№ 2.- с. 24-26.

4. Никифоров С. Л. К вопросу об использовании лучшего зарубежного опыта в реформировании российского аудита//Деньги и кредит.-2017.-№ 11.- с. 29-34.

5. Официальный сайт Минфина России [Электронный ресурс] URL: https://minfin.gov.ru/ru/perfomance/audit/ audit_stat/MainIndex/ (дата обращения: 08.03.2021).

6. Официальный сайт рейтингового агентства РАЭКС-Аналитика [Электронный ресурс] URL: https://raex-a.ru/ (дата обращения: 08.03.2021).

7. Официальный сайт Росстата [Электронный ресурс] URL: https://rosstat.gov.ru/storage/mediabank/94cQBbmp/ tab1.htm (дата обращения: 08.03.2021).

8. Официальный сайт Саморегулируемой организации аудиторов Ассоциации «Содружество» [Электронный ресурс] URL: https://auditor-sro.org/about/fond/ (дата обращения: 28.05.2021).

9. Приказ Минфина России от 28.06.2010 N 63н «Об утверждении Положения по бухгалтерскому учету «Исправление ошибок в бухгалтерском учете и отчетности» (ПБУ 22/2010)»

10. Федеральный закон от 01.12.2007 N 315-Ф3 «О саморегулируемых организациях».

11. Федеральный закон от 30.12.2008 N 307-ФЗ «Об аудиторской деятельности».

12. Kotler P, Armstrong G. Principles of marketing. - New Jersey: Upper saddle river, 2001.-1200 p.

13. Robertson J. C. Auditing.- Homewood: Richard D. Irwin, Inc.,1990.-765 p.

14. Shared and joint audits: are two auditors better than one? [Электронный ресурс] https://www.icaew.com/ technical/thought-leadership/audit-and-assurance-thought-leadership/shared-and-joint-audits-are-twoauditors-better-than-one (дата обращения: 27.05.2021). 